\title{
Research of Damage Evolution of 2219 Aluminum Alloy Weld Hole Based on ANSYS
}

\author{
Ping Zhang ${ }^{1,2, a}$, Xiao Yu ${ }^{2, b}$, Yuanyuan $\mathrm{Li}^{2, \mathrm{c}}$, Youqiang Wang ${ }^{1, \mathrm{~d},{ }^{*}}$ \\ ${ }^{1}$ School of Mechanical Engineering, Qingdao University of Technology, Shandong Qingdao, \\ 266520 \\ 2School of Mechanical Engineering, Qingdao Huanghai University, Qingdao 266033, China \\ a18661660729@163.com, b434463230@qq.com, c568146084@qq.com, \\ dwyq1970301@126.com
}

Keywords: 2219 aluminum alloy; Weld; microvoid; Stress concentration; Ligament width.

\begin{abstract}
In order to explore the influence mechanism of micropores on the stress concentration of 2219 aluminum alloy welds, 2219 aluminum alloy was selected as the research object in this paper, and establishes the finite element model of single hole and double hole based on ANSYS finite element analysis software. The influence of the size, position and shape of the single hole and the double hole on the stress concentration of the weld. The finite element simulation results show that the stress concentration direction of a single hole is always the same as the short axis direction of the ellipse, and the maximum stress and the hole radius show a significant positive correlation between the maximum stress of the weld and the distance between the hole and the weld center And the maximum stress between the maximum stress in the X-direction of the double-hole and the width of the ligament is positively correlated and linearly related. The maximum stress and the ligament width in the Y-direction show a tendency to decrease first and then stabilize. Characteristics, the greater the width of the ligament, the greater the greater the stress.
\end{abstract}

\section{Introduction}

2219 aluminum alloy is a typical high-strength aluminum alloy, because of its low density, high strength, specific stiffness and high stiffness and corrosion resistance, etc., was selected as the preferred lightweight armored vehicles. Today, the international environment more and more serious, arms competition related to the country's main position, 2219 aluminum alloy is the preferred material of the military chemical industry, and most of the main components as a result of welding, therefore, 2219 aluminum alloy welding quality It is particularly important, by domestic and foreign experts and scholars of all ages, and carried out a lot of research, but also emerged some of the relevant results. In the domestic, Li Yanjun and others on the 2219 aluminum alloy VPTIG welding residual stress were analyzed; Zhou Li, who studied the 2219 aluminum alloy friction stir welding head defects and welding methods; Guo Ran and others studied the 2219 aluminum alloy welded joints And the tensile properties of the 2219 aluminum alloy welded joint were studied. The effects of the welding method on the mechanical properties of the welded joint of the 2219 aluminum alloy were studied. The effects of the welding method on the mechanical properties of the welded joint of the 2219 aluminum alloy were studied. The results show that the fracture behavior of 2219 aluminum alloy compound welding source and the welding joint are studied. The corrosion characteristics of 2219 aluminum alloy friction stir welding joint are studied. PENG Xing-na et al. Studied the effect of welding method on the properties and microstructure of 2219 aluminum alloy base metal. Although domestic and foreign experts and scholars on the 2219 aluminum alloy welding and other aspects of research has become more mature, but most of the weld in the neglect of micro-holes and other aspects of research, therefore, this article to 2219 aluminum alloy as the object of study, based on ANSYS The finite element analysis software explores the effect of the size, shape and position of the single hole, the size 
and position of the double hole on the stress concentration of the weld, and will make a good reference to the micro-damage of the 2219 aluminum alloy.

\section{2. micro - hole welded joint model}

Considering the influence of various factors in the welding process, there are microvoids in the weld, and the shape of the micropores presents diversity, which has caused the study of the micro-hole damage mechanism of the material. The shape of the micropores is defined as oval. The mathematical model is shown in equation (1).

$$
\frac{\left(x-x_{0}\right)}{a^{2}}+\frac{\left(y-y_{0}\right)}{b^{2}}=1
$$

Where: $\left(x_{0}, y_{0}\right)$ is the micro-hole center coordinates, a and $\mathrm{b}$, respectively, for the oval-shaped micro-hole to the half-axis length. The form of welded joints is simplified as the "sandwich" form of the base metal - weld - base material, as shown in Figure 1.

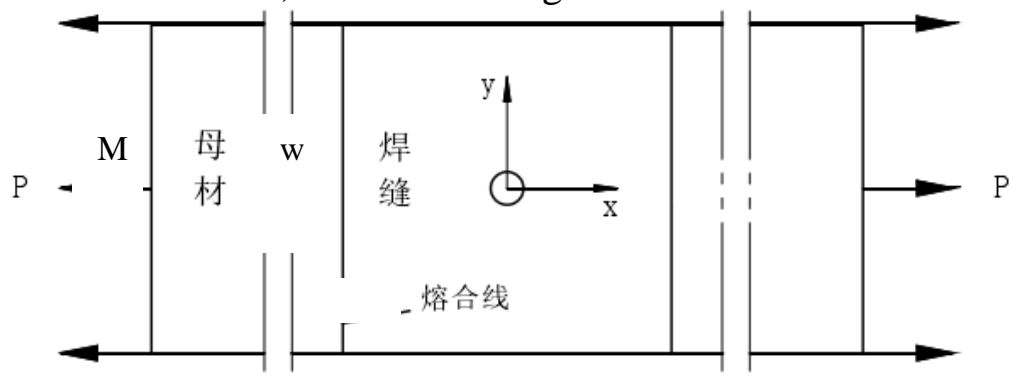

Figure 1. Weld form

Before the finite element simulation of the microvoid damage of the welded joint, the fracture form of the welded joint should be defined according to the actual situation. In this paper, the fracture model of the welded joint is studied by the experimental method. The microvoid hole is designed and stretched at the center of the weld. The experimental results show that the fracture of the welded joint does not show obvious necking the results show that the fracture form of the 2219 aluminum alloy welded joint can be defined as brittle fracture, so the finite element model of the welded joint can be considered as the linear elastic model for analysis.

\section{3. finite element analysis}

\subsection{Effect of hole shape on stress concentration of weld}

The stress concentration of the hole in the weld is mainly expressed as the influence of the hole angle on the stress concentration. The definition of the hole angle can be expressed according to the ratio of the long axis and the short axis. When the ratio is 0 , it shows the microcrack, The larger the ratio of the axle and the short axis, the closer the shape of the micropores is to the circle. When the ratio is 1 , the shape of the micropores is circular. Considering the shape of the hole is defined as oval, therefore, this part discusses the micro-hole along the semi-axial length ratio of the stress concentration of the weld.

Figure 2 (a) and (b) show the finite element analysis of the micropores of two shapes of $a / b=0.5$ and $\mathrm{b} / \mathrm{a}=0.5$, respectively. It can be seen from Fig. 2 that when $\mathrm{a} / \mathrm{b}=0.5$, the stress concentration is obvious along the $\mathrm{x}$-axis direction. When $\mathrm{b} / \mathrm{a}=0.5$, the stress concentration is obvious along the $\mathrm{y}$-axis direction.

Figure 3 depicts the effects of different shapes of microvoids on the maximum stress. It can be seen from Fig. 3 that with the increase of the ratio of $b$ / a, the maximum stress of 2219 aluminum alloy welds shows a decreasing trend. With the increase of the ratio of a / b, 2219 aluminum alloy Of the maximum stress showed a linear increase in the trend. 


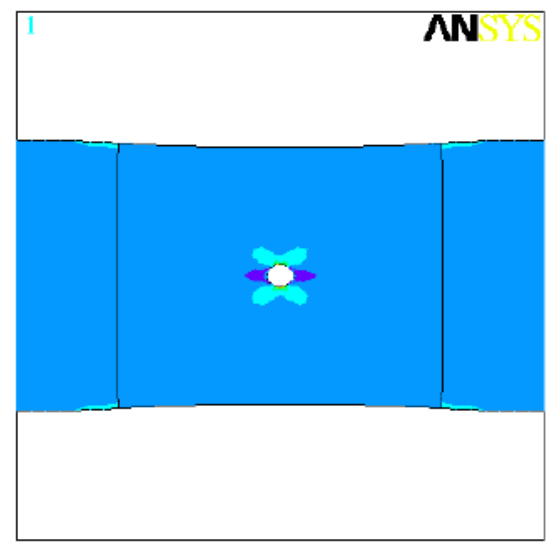

(a)

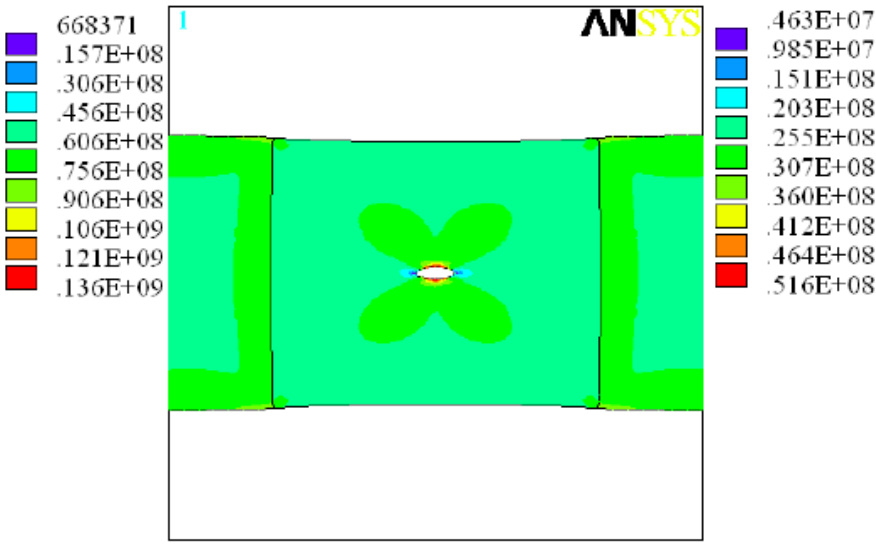

(b)

Fig.2 Stress cloud diagram of different shapes of microvoids

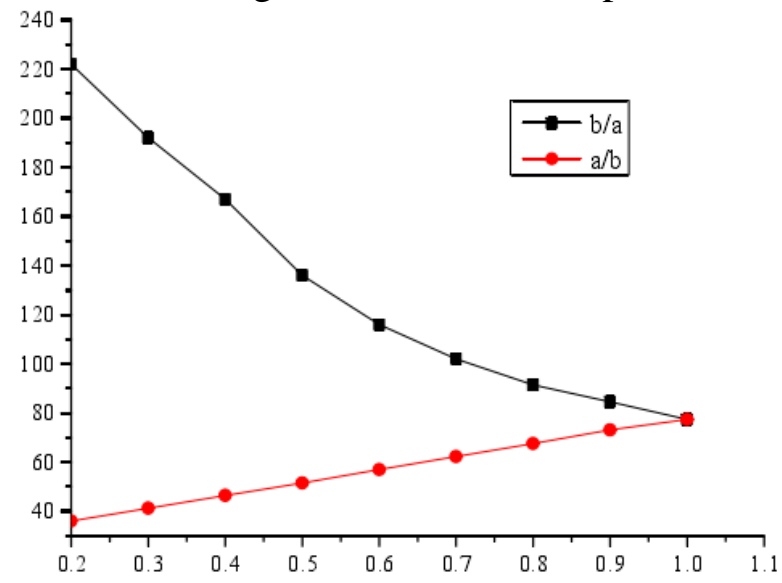

Fig.3 Maximum stress relationship under different shapes of microvoids

\subsection{Effect of hole size on stress concentration}

In addition to the shape of the micro-hole on the weld stress concentration has a greater impact, the size of the micro-hole on its impact cannot be ignored. Figure 4 shows the stress cloud of microvoids under different operating conditions. Fig. 4 (a) shows the stress cloud when the center hole is $0.5 \mathrm{~mm}$; Fig. 4 (b) shows the stress cloud when the hole is $0.8 \mathrm{~mm}$ in the center; Fig. 4 (c) is the hole size of $3 \mathrm{~mm}$ away from the center Fig. 4 (e) is a stress cloud diagram with a hole size of $0.5 \mathrm{~mm}$ when the hole is $4 \mathrm{~mm}$ away from the center position; Fig. 4 (d) is a stress cloud diagram with a hole size of 0.8 $\mathrm{mm}$ from the center position of Fig. 4 (f) is a stress cloud image with a hole size of $0.8 \mathrm{~mm}$ deviated from the center position of $4 \mathrm{~mm}$. According to the stress cloud diagram in Figure 4, the relationship between the maximum stress and the size and position is shown in Fig. It can be seen from Fig. 5 that there is a significant positive correlation between the maximum stress and the radius of the hole. The reason is that with the increase of the size of the hole, the force area of the same section decreases, resulting in stress concentration The farther away from the center, the more concentrated the stress concentration phenomenon, the reason is: the distance from the center of the farther away, said the location of the hole closer to the $\mathrm{X}$ and $\mathrm{Y}$ direction of the edge, $\mathrm{X}$ to The edge of the edge of the fusion line near the welding heat stress in this region is higher, the existence of holes more likely to induce nucleation, grow up to damage; $Y$ to the edge of the weld is the outermost side of the weld due to the welding process The welding heat does not come out of time and causes the welding residual stress. At the edge of the weld, there is a large residual tensile stress, and the existence of the hole in the residual tensile stress coupling effect, resulting in more concentrated stress. 


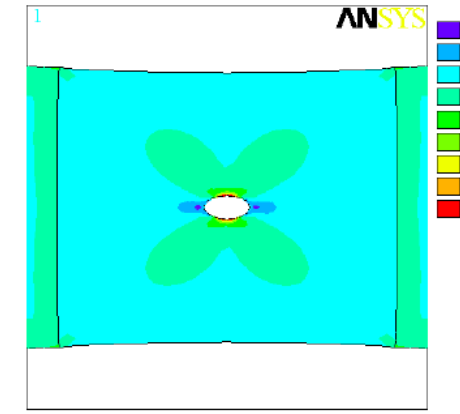

(a)

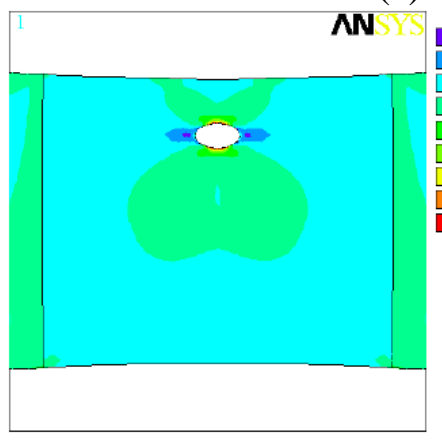

(c)

)

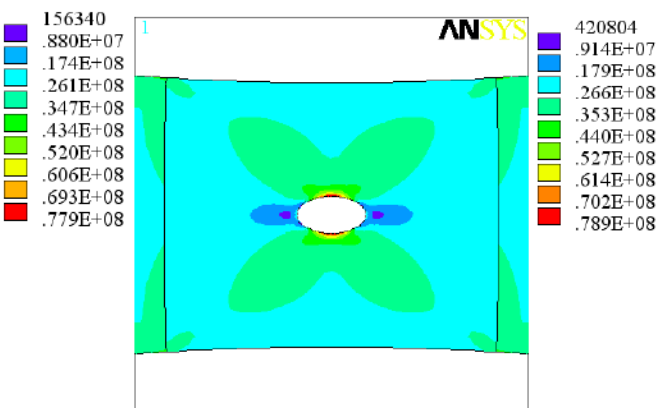

(b)

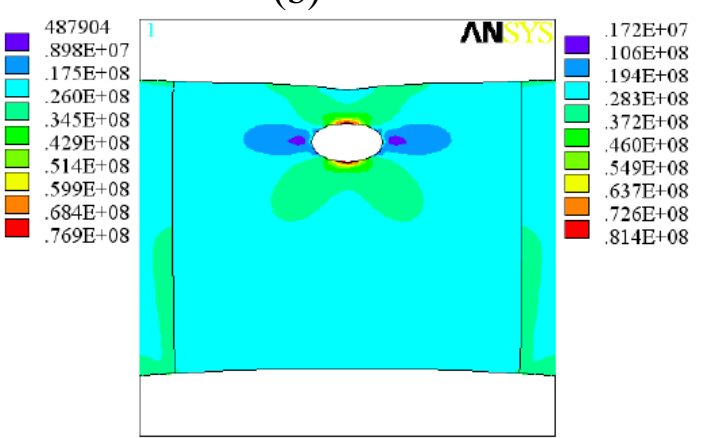

(d)

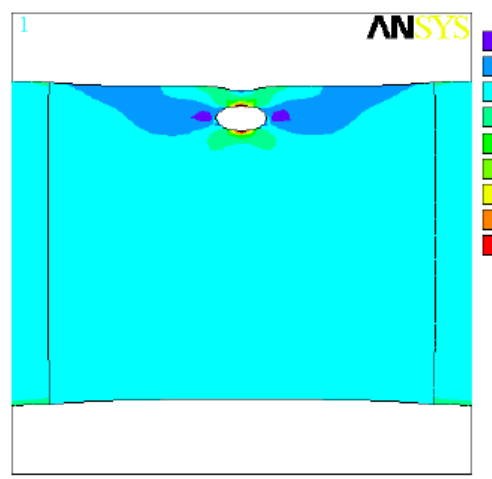

(e)

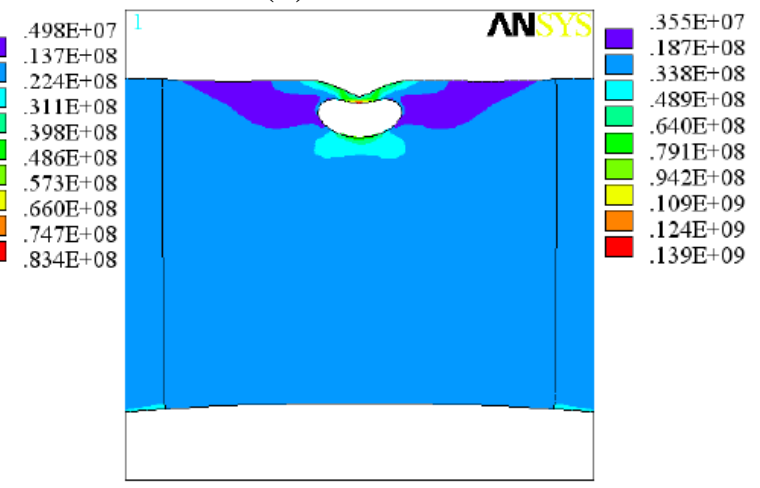

(f)

Figure 4. Stress clouds at different sizes

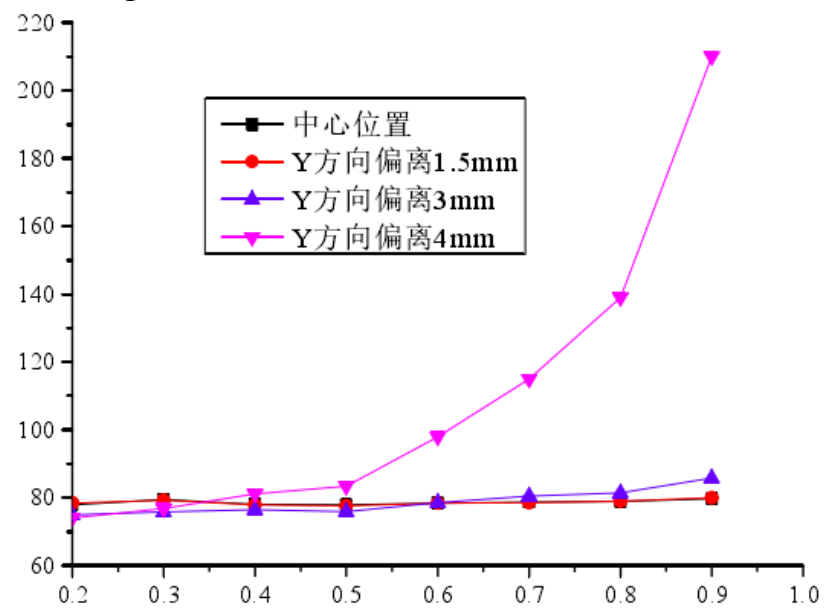

Fig.5 Maximum stress relationship under different working conditions

\subsection{Effect of double hole ligament width on stress concentration}

During the welding process, the distribution and number of holes are random, and the ligament width between the double holes has a significant effect on the stress concentration of the holes. Figure 6 shows the stress profiles of different ligaments in different directions. Figure 6 (a) and (b) show the stress cloud in the X-direction ligament width of $0.75 \mathrm{~mm}$ and $1.25 \mathrm{~mm}$, respectively. Figure 6 (c) and (d) show the stress profiles of the ligament widths of $0.75 \mathrm{~mm}$ and $1.25 \mathrm{~mm}$ in the $\mathrm{Y}$ direction. The relationship between the maximum stress and the ligament width of the maximum stress finishing 
under different working conditions is shown in Fig. 6. It can be seen from Fig. 7 that there is a positive correlation between the maximum stress in the $\mathrm{X}$ direction and the ligament width, and the linear correlation is related. The reason is that the $\mathrm{X}$ direction is the direction of the tensile force, and as the ligament width gradually increases, The nucleus of the ligament region between the holes becomes narrow elongated, resulting in the maximum stress increases; the maximum stress in the $\mathrm{Y}$ direction and the ligament width tend to decrease first and then stabilize the final increase, the ligament width is less than $0.5 \mathrm{~mm}$, the maximum stress reduction rate is the fastest; the reason is: when the ligament width is less than $0.5 \mathrm{~mm}$, the weld received tension and make the two holes of the ligament width of the rapid narrowing, more likely to occur through the hole; When the ligament width is greater than $2.5 \mathrm{~mm}$, the weld is subject to the same tensile force, the ligament area does not form an effective nucleation area, therefore, will not produce a hole through phenomenon, due to the same cross-section of the force area, Resulting in the maximum stress showing an increasing trend.

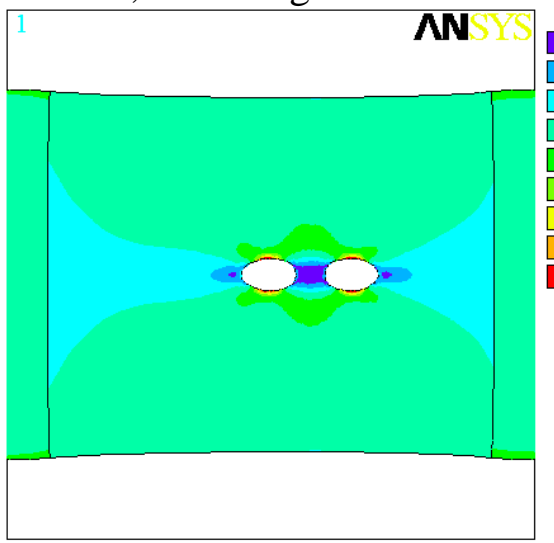

(a)

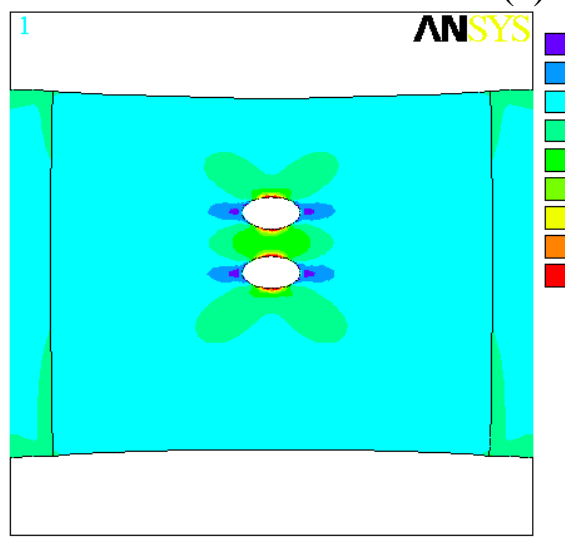

(c)
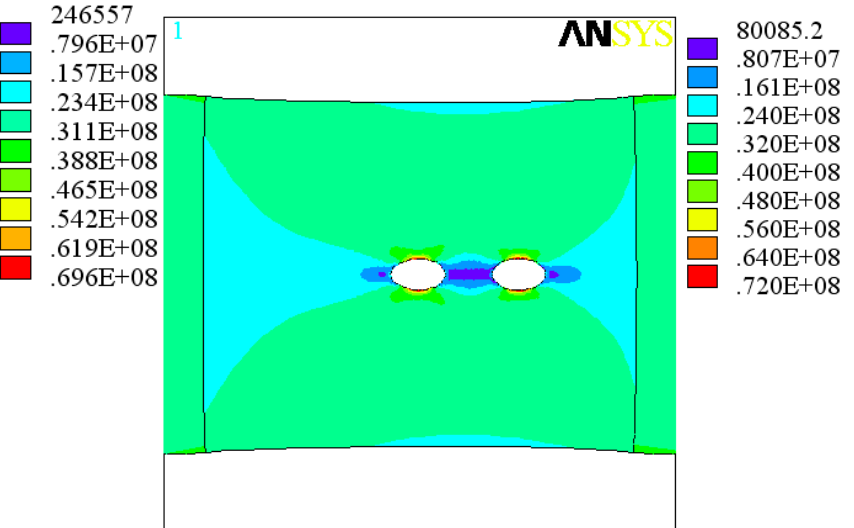

(b)

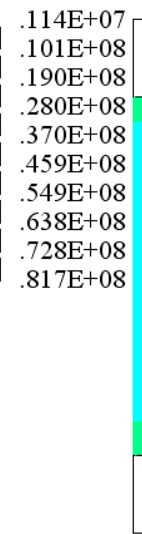

(d)

Figure 6. Stress maps of different ligament widths

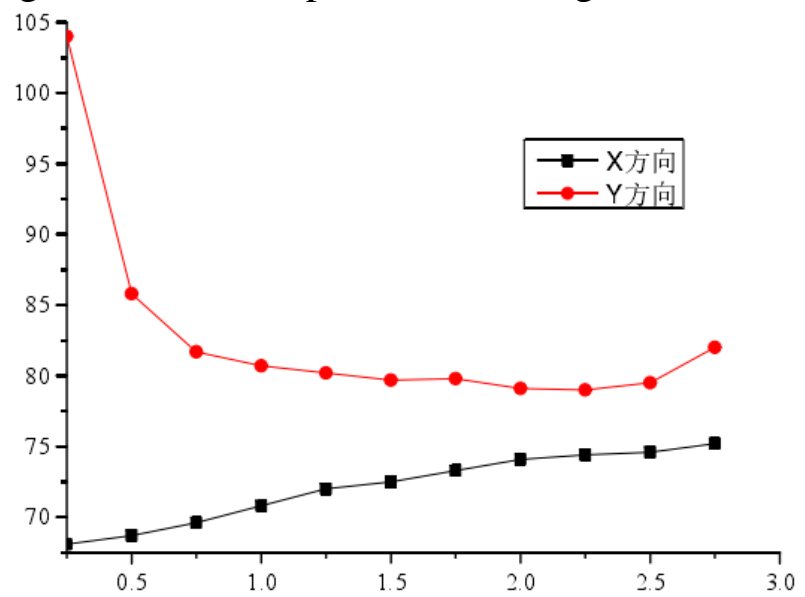

Figure 7. Effect of ligament width on maximum stress 


\subsection{Effects of different sizes of double holes on stress concentration}

In order to maintain a single variable, the size of the hole below the constant is $0.5 \mathrm{~mm}$, change the size of the hole above, and explore the effect of the whole size on the stress concentration. At the same time, change the effect of the double hole on the stress concentration. The distance between the two holes, and explore the effect of the ligament width on the stress concentration.

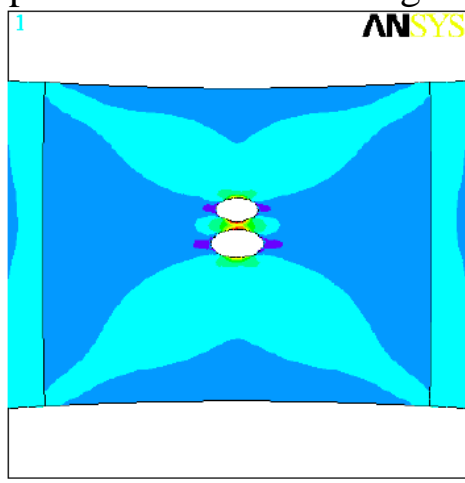

(a)

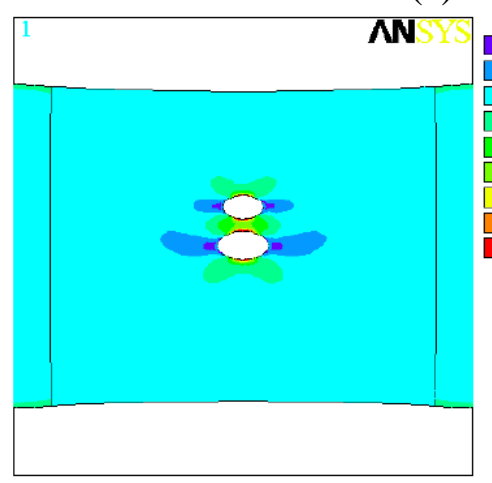

(c)

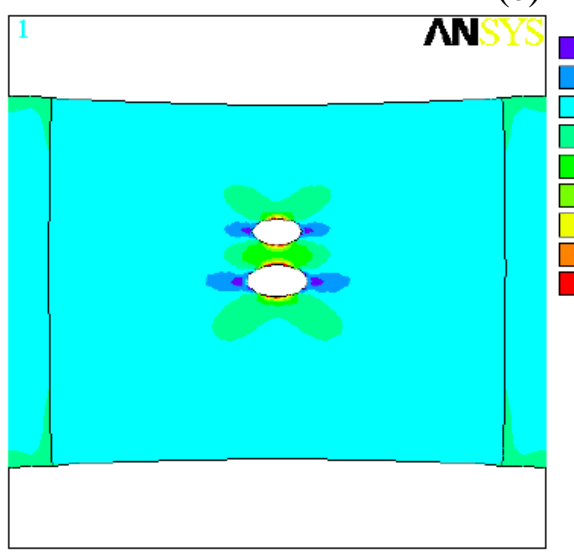

(e)
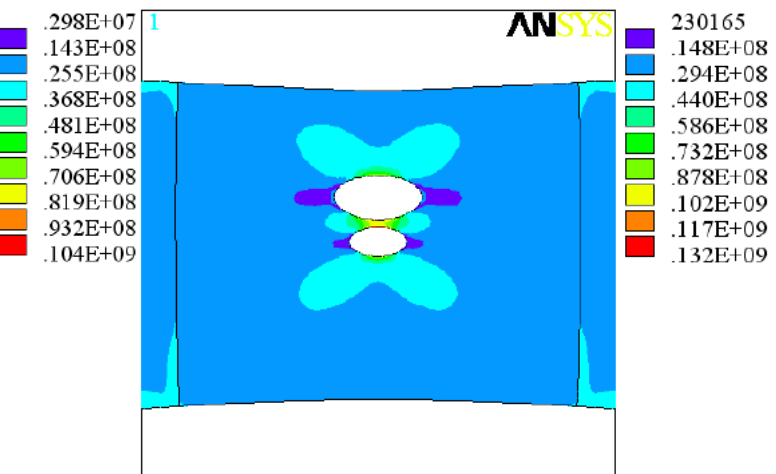

(b)

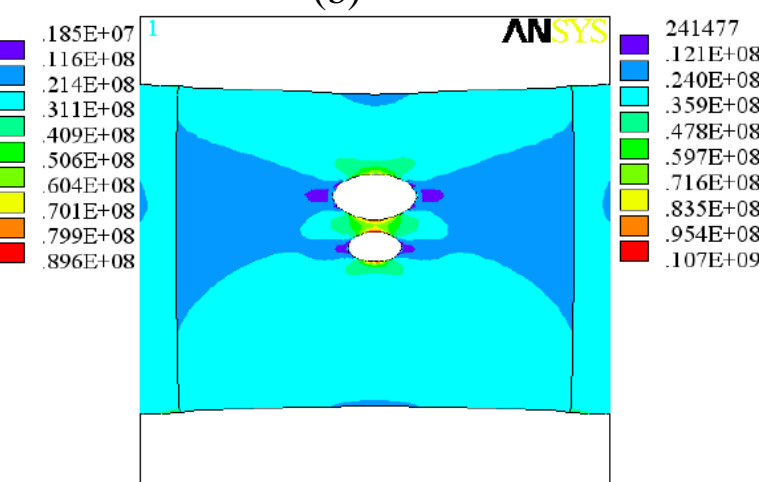

(d)

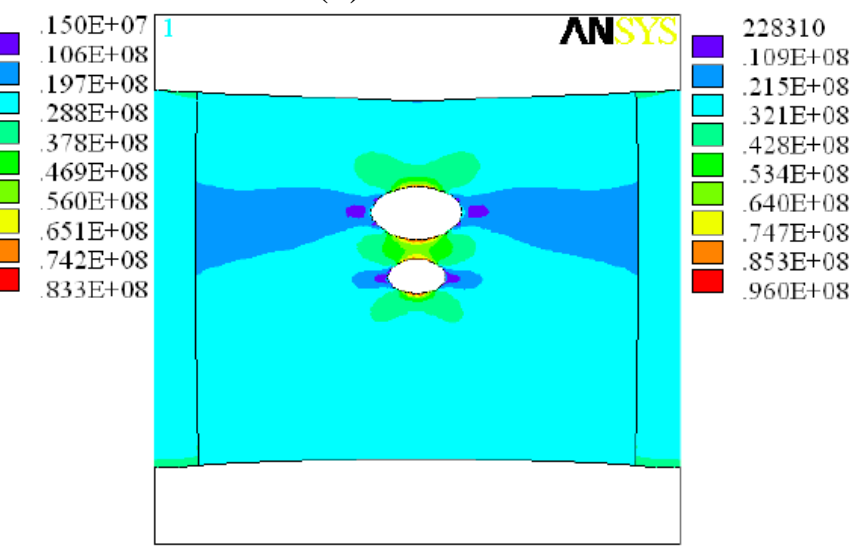

(f)

Figure 8. Stress maps of double holes with different sizes

Figure 8 shows the stress profile for different whole sizes and ligament widths. Figure 8 (a), (c) and (e) show a stress cloud of $0.25 \mathrm{~mm}, 0.4 \mathrm{~mm}$ and $0.55 \mathrm{~mm}$, respectively, when the upper hole size is $0.4 \mathrm{~mm}$, respectively. Figures 8 (b), (d) and F), respectively, when the whole size of $0.8 \mathrm{~mm}$, the ligament width were $0.25 \mathrm{~mm}, 0.4 \mathrm{~mm}$ and $0.55 \mathrm{~mm}$ stress cloud. It can be seen from Figure 8: the same ligament width, the larger the size of the hole, the stress concentration is more obvious; through the maximum stress obtained in Figure 8 finishing, drawing different sizes of double holes on the maximum stress of the relationship shown in Figure 9. According to Figure 9, it can be seen that there is a significant positive correlation between the maximum stress and the void size. The reason is that the larger the hole size is, the greater the difference between the two hole sizes is easy at the edge of the large hole The larger the nucleation and growth, the larger the size, the greater the nucleation is also easier, and ultimately the formation of cracks in the ligament region, the phenomenon of large holes to eat small holes, therefore, the maximum stress and void size between the positive correlation; 
The larger the ligament width, the greater the stress the smaller the reason that the greater the ligament width, the greater the coupling between the two holes, the stress concentration will occur at the edge of each hole, resulting in ligament area stress concentration weakened.

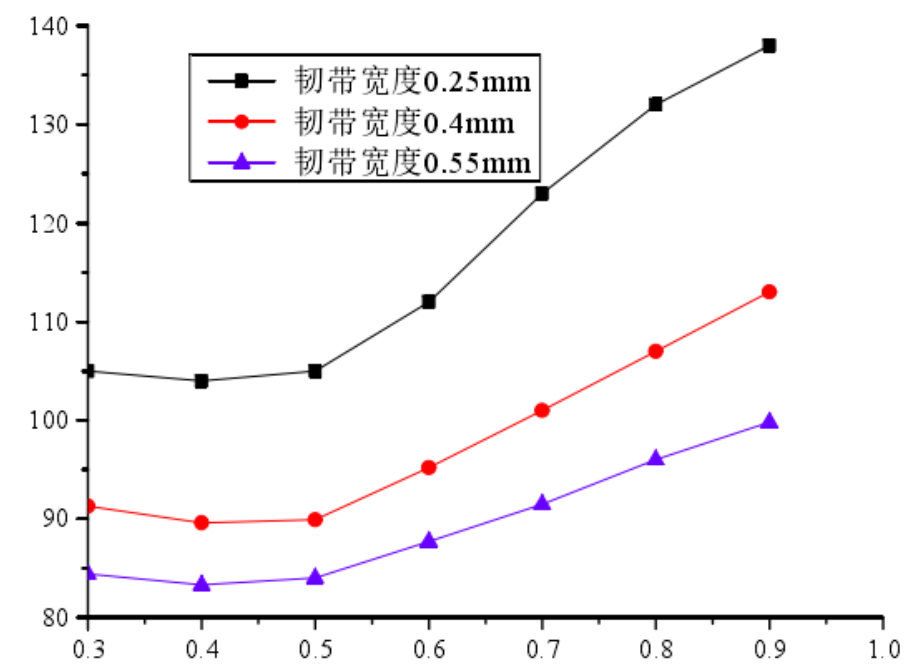

Fig.9 The relationship between the two holes with different sizes on the maximum stress

\section{Conclusion}

(1) a / b < 1 stress concentration along the $\mathrm{X}$ direction, and the maximum stress and a / $\mathrm{b}$ ratio showed a significant negative correlation; $\mathrm{b} / \mathrm{a}<1$ stress concentration along the $\mathrm{Y}$ direction, this time, the maximum stress and $\mathrm{b} / \mathrm{a}$ Of the ratio showed a significant positive correlation, and showed a linear correlation.

(2) There is a significant positive correlation between the maximum stress and the radius of the hole, and the distance from the center of the hole is small

At $3 \mathrm{~mm}$, the effect of the position on the maximum stress of the welding is not obvious; the void position is greater than $3 \mathrm{~mm}$ from the center of the weld, and the maximum stress and distance of the weld are positively correlated.

(3) When the double hole has a positive correlation between the maximum stress in the X direction and the ligament width, and the linear correlation is related to the maximum stress and the ligament width in the Y direction, When the ligament width is less than $0.5 \mathrm{~mm}$, the maximum stress reduction rate is the fastest; the maximum stress and the void size show a significant positive correlation, the greater the ligament width, the smaller the maximum stress.

\section{Acknowledgements}

This paper is supported by the National Natural Science Foundation of China (51575289); Shandong Provincial Natural Science Foundation of China (ZR2016EEP03); Shandong University Science and Technology Program (J17KA031).

\section{References}

[1]. (Li Yanjun, Wu Aiping, Liu Debo, Zhao Haiyan, Zhao Yue, Wang Guoqing.Numerical analysis of welding residual stress of VPTA in 2219 aluminum alloy [J]. Journal of Tsinghua University (Science and Technology), 2016 (10): 1037-1041 + 1046 The

[2]. Zhou Li, Han Ke, Liu Chaolei, Huang Cheng, Chang Zhilong, Wu Huijiang, Feng Jicai, Meng Fanxin. 2219 aluminum alloy friction stir welding joint defect welding [J]. Journal of Aeronautical Materials, 2016, (01): 26- 32.

[3]. Guo Ran. Analysis of mechanical properties and crack propagation behavior of 2219 aluminum alloy welded joint [J]. Foundry Technology, 2015, (03): 741-743. 
[4]. Li Leping, Liu Xuejun, Qu Wenqing. Analysis of Tensile Properties of 2219 Aluminum Alloy VPTIG Welded Joints [J]. Aerospace Materials Technology, 2013, (06): 84-87.

[5]. Zhang Dan, Chen Wenhua, Sun Yaohua, Dong Fengbo. Effect of welding method on mechanical properties of welded joints of 2219 aluminum alloy [J]. Journal of Aeronautical Materials, 2013, (01): 45-49.

[6]. ZHAO Yan-hua, LI Yan-min, HAO Yun-fei, CHEN Yu-yun, WANG Guo-qing.Analysis of microstructure and properties of 2219 aluminum alloy double-shoulder friction stir welding joint [J]. Aerospace Materials Technology, 2012, (06): 70-75 + 91.

[7]. Ran Guowei, Song Yonglun, Yan Sibo, Lin Jiangbo. 2219 aluminum alloy composite heat source welding process and joint performance [J]. Welding Journal, 2011, (09): 25-29 + 114 .

[8]. Wu Hongyan, Xing Li, Chen Yuhua, Huang Chunping. Fracture characteristics of 2219 aluminum alloy friction stir welding joints [J]. Metal Heat Treatment, 2011, (05): 90-93.

[9]. Peng Peng, Qu Wenqing, Zhang Guohua. Effects of welding methods on the properties and microstructure of 2219 aluminum alloy [J]. Proceedings of the aerospace society, 2009, (02): 57-60.

[10]. Kramer L S, Blair T P, Blough S D. Stress-corrosi on cracking susceptibility of various product forms of aluminum alloy 2519 [J] .Materials Engineering and Performance, 2002, 11 (6): $645 \sim 650$.

[11]. Thaulow C, Zhang Z L. Numerical simulation of specimen size and mismatch effects in ductile crack growth-part I: tearing resistance and crack growth paths $[\mathrm{J}]$. Engineering Fracture Mechanics, 2007, 74: $1770 \sim 1792$.

[12]. TAN Bing, LIU Hong-wei, CHEN Dong-gao, ZHONG Zhu, WANG Fa-ke, KANG Zhen-yu.Study on Deformation Simulation of Laser-MIG Composite Welding of Aluminum Alloy Angular Joint Based on SYSWELD [J]. Journal of Materials Science and Engineering, 2011, (04): 48- 52. 